\title{
ALGORITHM FOR MODELLING THE REMOVAL OF SNOW FROM STRECHES OF THE MANOEUVRING AERA OF AN AIRPORT
}

\author{
César Marín Fernández \\ Aerospace Systems, Air Transport and Airports Department \\ UPM (Polytechnic University of Madrid). School of Aeronautical and Space \\ Engineering \\ Víctor Fernando Gómez Comendador \\ Aerospace Systems, Air Transport and Airports Department \\ UPM (Polytechnic University of Madrid). School of Aeronautical and Space \\ Engineering \\ Rosa María Aranaldo Valdés \\ Aerospace Systems, Air Transport and Airports Department \\ UPM (Polytechnic University of Madrid). School of Aeronautical and Space \\ Engineering
}

\begin{abstract}
This article presents an algorithm and a structured methodology to address the issue of the optimisation of resources when clearing snow from stretches of the manoeuvring area of an airport. This overall issue is how to best utilise limited resources to remove snow from taxiways and runways so as to leave surfaces in an acceptable state for aircraft operations. To achieve this the airfield is divided into subsets of significant stretches for the purpose of operations and target times are set at which these are to be open to aircraft traffic. The manoeuvring area is also divided into zones, with the condition that the subsets of significant stretches lie within just one of these zones. The mathematical model contains operating restrictions with regard to the fulfilment of partial operational targets applied to the subsets of significant stretches, and also concerning the snow-clearing machines. The problem is solved by an iterative optimisation process based on linear programming applied successively to the zones that make up the manoeuvring area during each iteration. The method is particularised for the case of the manoeuvring area of Adolfo Suarez Madrid - Barajas Airport.
\end{abstract}




\section{Introduction}

With increasing demand at airports it is important to ensure that down-time is kept to a minimum. In winter, snow on the manoeuvring area can be a serious impediment and having a correctly designed and well co-ordinated Winter Plan in place can help to overcome most contingencies. This article shows how it is possible to optimise the snow-clearing operation at an airport thereby achieving significant savings in time and minimising disruption. The time savings achieved may be as much as $30 \%$.

The problem is that the methods used in the case of a significant increase in demand are not effective or consistent in dealing with situations where there is a reduction in capacity. This is because they do not take account of variables that reduce the airport's normal capacity, such as meteorological variables, or because they are not applied in coordination with other affected airports (Eurocontrol, Airport CDM Coordination Group, 2009).

The objective of the operating procedures for dealing with snow conditions is to clear the airfield to ensure the safe operation of airside traffic. There is a need to develop tools to manage Winter Operations and procedures for estimating the friction coefficient of the pavements of contaminated runways(EASA, 2010).

There is a need to develop operational tools to assist in optimising the use of airport resources and infrastructure during Winter Operations. (AENA, S.A., 2013).

The resources for clearing snow at an airport are scarce and their use must be optimised both when clearing the airfield and when de-icing aircraft. Following heavy snowfall, an airport faces a contingency situation which it must be prepared for by adequate sizing of the physical and human resources, and appropriate education and training.

Within the context of discrete-time optimisation models for tactical production planning, this paper provides an algorithm for optimising the sequence for clearing stretches of the manoeuvring area so as to achieve better management of resources. The LP model is solved using a CPLEX branch-and-bound algorithm.

\section{Methodology for solving the problem of RM-MA}

\subsection{Algorithmic for tackling the problem of RM-MA}

The algorithm for solving the problem of the management of resources in the Winter Plan for clearing snow from the manoeuvring area of an airport shall be known as RMMA. It will tackle the problem using a scheduling theory approach by considering a machine that removes snow from contaminated runways and taxiways.

The problem may be stated as:

$$
1 / p_{\mathrm{i}}, \delta_{\mathrm{ij}} / \Sigma \omega_{\mathrm{z}} \mathbf{l}_{\mathrm{z} \text { mix }}
$$

Given a set $\mathrm{J}=(1,2, \ldots, \mathrm{n})$ of $\mathrm{N}$ nodes which comprise a manoeuvring area. Each stretch between two nodes corresponds to stretch of the manoeuvring area from which snow must be removed to provide service to a set $\mathrm{I}=(1,2, \ldots, \mathrm{z})$ of $\mathrm{Z}$ aircraft that must land / 
take-off / park within a planned period of time. Therefore, the queue of stretches to be cleared forms a set $\mathrm{J}^{\prime}=(\mathrm{i} 1, \mathrm{i} 2, \ldots, \mathrm{ik}, \mathrm{ik}+1, \ldots, \mathrm{im})$ of $\mathrm{M}$ elements. Given the complex geometry of the manoeuvring area there might be stretches where clearing may be repeated to ensure that all the stretches are cleared. Therefore, $m \geq n$. We find that $m=n$ only where the geometry of the manoeuvring area is very simple, as one can imagine, and as will be seen in this study.

We will consider $\mathrm{H}$ significant areas in the manoeuvring area. Each of these significant areas corresponds to a subset $\mathrm{i}$ of the stretches of the set $\mathrm{J}=(1,2, \ldots, \mathrm{n})$ of $\mathrm{N}$ stretches that make up the manoeuvring area.

Each subset of significant points consists of one or more stretches $\mathrm{i}$, and form $\mathrm{H}$ subsets whose union $\mathrm{J}^{\prime} \subset \mathrm{J}$. Where $\mathrm{J}_{\mathrm{z}}$ is a subset of set $\mathrm{J}^{\prime}=\left(\mathrm{J}_{1}, \mathrm{~J}_{2}, \ldots, \mathrm{J}_{\mathrm{z}}, \ldots, \mathrm{J}_{\mathrm{h}}\right)$. Where $\mathrm{t}$ is a stretch of the subset $J_{z}=\left(1,2, \ldots, t, \ldots, q_{z}\right)$, which has $q_{z}$ stretches of the set $J$ and that only belong to $\mathrm{J}_{\mathrm{z}}$, not belonging to any other subset of significant points of the apron. Therefore:

$\mathrm{J}_{1} \cup \mathrm{J}_{2} \cup \ldots \cup \mathrm{J}_{\mathrm{Z}} \cup \ldots \cup \mathrm{J}_{\mathrm{h}}=\mathrm{J}^{\prime} \subset \mathrm{J} \quad \mathrm{J}_{\mathrm{Z}}=\left(1,2, \ldots, \mathrm{t}, \ldots, \mathrm{q}_{\mathrm{z}}\right) \subset \mathrm{J}$

$\mathrm{J}_{\mathrm{i}} \cap \mathrm{J}_{\mathrm{j}}=\varnothing$ with $\mathrm{i}, \mathrm{j} \in(1,2, \ldots, \mathrm{z}, \ldots, \mathrm{h})$

The $\mathrm{H}$ subsets of significant points for a generic manoeuvring area are:

- JRWY-Ai: Subset of stretches that make up runway i and rapid exit taxiways, up to access to the apron.

- J JWY-Di: Subset of stretches that make up take-off runway i and access taxiways to the head-of-runway, from the corresponding de-icing aprons.

- JZDe-icek: Subset of stretches of de-icing area k.

- JAPR: Subset of stretches of the aircraft parking apron, consisting of the inners of the apron.

- JAPR-ZDe-icek: Subset of stretches that provide access to de-icing apron k from the exit gate of the apron.

As previously mentioned, target times are set for significant areas of the manoeuvring area. For the abovementioned subsets these times are: rRWY-Ai, rRWY-Di, rZDe-icek, rAPR and rAPR-ZDe-icek.

Thus the main aim of the management of machines is to clear snow from each significant area as soon as possible. These intermediate finishing times for the

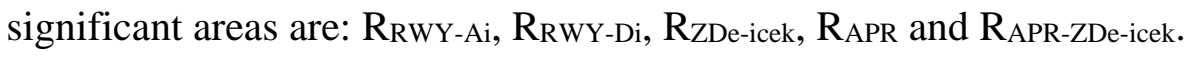

The data is as follows:

- $\mathbf{Z}_{0}$ : time at which the process of clearing snow from the manoeuvring area is initiated.

- $\mathbf{p}_{\mathbf{i}}$ : time taken to clear snow from stretch $\mathrm{i}$, bearing in mind the following parameters: 


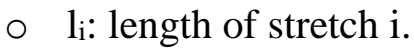

○ v: velocity of the snow-clearing convoy. Technology is implicit in this parameter since the yield of surface area cleared per unit of time depends on the velocity $\mathrm{v}$ at which the convoy advances.

- The velocity when crossing from one taxiway to another is taken to be half the velocity $\mathrm{v}$ along a safety stretch just before and after the crossing. This is to ensure safety in the manoeuvre when changing taxiways.

$$
p_{i}=\frac{l_{i}-l_{\text {safety }}}{v}+\frac{l_{\text {safety }}}{v / 2}
$$

- $\boldsymbol{\delta}_{\mathrm{ij}}$ : with a value of 1 if stretch $\mathrm{j}$ can be cleared after $\mathrm{i}$, value of 0 in the remainder (this takes the compatibility between one stretch and another into account, in line with the continuity of the layout).

- $\mathbf{r}_{\text {total }}$ : estimated time at which the manoeuvring area is cleared.

- $\mathbf{r}_{\mathrm{z}}$ : estimated time at which subset $\mathrm{z}$ of significant stretches of the manoeuvring area is clear.

The variables of the model are:

- $\mathbf{x}_{\mathbf{i j}}{ }^{\mathrm{k}}$ : decision variable, where $\mathrm{x}_{\mathrm{ij}}{ }^{\mathrm{k}}=1$ if stretch $\mathrm{i}$ directly precedes $\mathrm{j}$ in the $\mathrm{k}^{\text {th }}$ position; otherwise $\mathrm{x}_{\mathrm{ij}}{ }^{\mathrm{k}}=0$;

- $\mathbf{S i}_{\mathbf{i}}^{\mathbf{k}}$ : time at which clearing of stretch $\mathrm{i}$ in the $\mathrm{k}^{\text {th }}$ position starts;

- $\quad \mathbf{R}_{\mathbf{i}}^{\mathbf{k}}$ : actual time at which stretch $\mathrm{i}$ is cleared;

- $\mathbf{R}_{\text {max }}$ : maximum time for completing the removal of snow from the manoeuvring area.

- $\mathbf{R}_{\max \mathbf{z}}$ : actual time at which subset $\mathrm{z}$ of each subset of significant stretches that make up that subset is cleared.

$$
R_{z}=\max \left\{R_{1}, R_{2}, \ldots, R_{q_{z}}\right\} \quad \text { where } \mathrm{J}_{\mathrm{z}}=\left(1,2, \ldots, \mathrm{t}, \ldots, \mathrm{q}_{\mathrm{z}}\right) \subset \mathrm{J}
$$

- $\mathbf{I}_{\text {total }}$ delay in the manoeuvring area, defined as $1_{\text {total }}=\mathrm{R}_{\max }-\mathrm{r}_{\text {total }}$.

- $\mathbf{l}_{\mathbf{z}}$ : delay in the subset of significant stretches $\mathrm{z}$ of the manoeuvring area, given by $l_{\mathrm{z}}=\mathrm{R}_{\max \mathrm{z}}-\mathrm{r}_{\mathrm{z}}$.

- $\mathbf{p}_{\mathbf{i}}^{\mathbf{k}}$ : length of time for clearing snow from stretch $\mathrm{i}$ in the $\mathrm{k}^{\text {th }}$ position. Note: There are stretches in which snow can be cleared in just one pass and others, such as the runways, which require several passes and with different configurations of the machines. The equations of the model must be capable of clearing snow even from taxiways that have no exit, in other words, cul-de-sacs. In such cases the clearing time is doubled as the team has to go down the stretch, 
perform a U-turn and then return along the same stretch. However, the model is free to apply the same manoeuvre to passable stretches. For this reason the clearing time of a stretch depends on both the stretch and its position $\mathrm{k}$ in the queue.

The U-turn has been modelled using a semi-circular arc the radius of which is equal to the radius of turn of the snow-clearing machines at a safety speed v/2. Therefore:

- For stretches i which are passable in position $\mathrm{k}$ :

$$
p_{i}^{k}=p_{i}
$$

- For stretches i which require a U-turn in position $\mathrm{k}$ :

$$
p_{i}^{k}=2 p_{i}+\frac{\pi R_{\text {giro }}}{v^{\prime}}
$$

Model to solve the problem

\section{$1 / \mathbf{p}_{\mathbf{i}}, \delta_{\mathrm{ij}} / \Sigma \omega_{\mathrm{z}} \mathbf{l}_{\mathrm{z} \text { mix }}$}

has the following objective function:

$$
z=\frac{1}{B_{l}}\left(\sum_{z=1}^{h} \omega_{z} l_{z}+\omega_{\text {total }} l_{\text {total }}\right)
$$

with the following restrictions:

$$
\begin{aligned}
& \sum_{j=1}^{n} \delta_{i j} \cdot x_{i j}^{k}-\sum_{l=1}^{n} x_{l i}^{k-1}=0 \quad i=1, \ldots, n \quad k=2, \ldots, n \\
& \sum_{j=1}^{n} \delta_{1 j} \cdot x_{1 j}^{1}=1 \\
& \sum_{k=1}^{n} \sum_{j=1}^{n} x_{i j}^{k} \geq 1 \quad i=1, \ldots, n \\
& \sum_{i=1}^{n} \sum_{j=1}^{n} x_{i j}^{k}=1 \quad k=1, \ldots, n \\
& s_{j}^{k+1}+B i g M \geq R_{i}^{k}+B i g M \cdot x_{i j}^{k} \quad i=1, \ldots, n j=1, \ldots, n k=1, \ldots, n i \neq j \\
& R_{i}^{k} \leq R_{\max } \quad i=1, \ldots, n \quad k=1, \ldots, m \\
& R_{i}^{k}+B i g M \geq s_{i}^{k}+p_{i}^{k}+B i g M \cdot x_{i j}^{k} \quad i=1, \ldots, n \quad k=1, \ldots, m i \neq j
\end{aligned}
$$

$$
\begin{aligned}
& p_{i}^{k} \geq p_{i} \\
& i=1, \ldots, n \\
& p_{i}^{k}+2 B i g M \geq 2 p_{i}+t_{\text {pen_giro }}+B i g M \cdot\left(x_{l i}^{k-1}+x_{i j}^{k}\right) \\
& i \neq j \quad j, l=1, \ldots, n \text { only if } j=l \text { or } \delta_{l j}=1 \\
& s_{1}^{1} \geq R_{0} \\
& j=1, \ldots, n \\
& x_{i j}^{k}=0 \\
& i \in r w y \\
& j=1, \ldots, n \quad k=m \quad i \neq j \\
& R_{t}^{k} \leq R_{\max z} \\
& z=1, \ldots, h \quad t=1, \ldots, q_{z} \quad k=1, \ldots, m \\
& l_{z} \geq R_{\max z}-r_{z} \\
& z=1, \ldots, h \\
& l_{\text {total }} \geq R_{\text {max }}-r_{\text {total }} \\
& z=1, \ldots, h
\end{aligned}
$$


with the addition of:

$$
\begin{array}{llll}
x_{i j}^{k} \in\{0,1\} & \forall k, \forall(i, j) & s_{i}^{k}, R_{i}^{k}, p_{i}^{k} \geq 0 \forall k, \forall i \quad l_{z} \geq 0 \forall z & R_{\text {max }}, Z_{0} \geq 0 \\
0 \leq \omega_{i}, \omega_{\text {total }} \leq 1 & r_{z} \geq 0 \mathrm{y} R_{z} \geq 0 \quad z=1, \ldots, h
\end{array}
$$

$\mathrm{B}_{1}$ is a parameter that makes each of the sums that intervene in the objective function (4.2) non-dimensional. $\mathrm{B}_{1}$ is given by the expression:

for $z=1, \ldots, h$.

$$
B_{l}=r_{\text {total }}-\sum_{i=1}^{n} p_{i}
$$

Restriction (1.2) ensures continuity between stretches. Restriction (1.3) requires clearing to begin at stretch 1 with no restriction on the finishing stretch. Restriction (1.4) requires all stretches to be in the queue and, furthermore, they can be there on more than one occasion. Restriction (1.5) requires each position $\mathrm{k}$ to be an exact arc. Restriction (1.6) means that there is separation between two successive cleared stretches. Restriction (1.7) defines the maximum length of time for clearing stretches. Inequality (1.8) defines $\mathrm{R}_{\mathrm{i}}^{\mathrm{k}}$ as the sum of $\mathrm{si}^{\mathrm{k}}$ and $\mathrm{p}_{\mathrm{i}}^{\mathrm{k}}$, when $\mathrm{i}$ precedes $\mathrm{j}$ in the $\mathrm{k}^{\text {th }}$ position. Inequality (1.9) states that the minimum processing time of each stretch $\mathrm{i}$ in the $\mathrm{k}^{\text {th }}$ position is $\mathrm{p}_{\mathrm{i}}$, in other words, as if the stretch was passable. Inequality (1.10) deals with the situation where the stretch is processed in both directions, in other words, those cases in which stretch $\mathrm{j}$ which continues on from stretch $\mathrm{i}$ in the $\mathrm{k}+1^{\text {th }}$ position is equal to stretch 1 which precedes stretch $\mathrm{i}$ in the $\mathrm{k}-1^{\text {th }}$ position, or where $\mathrm{j}$ belongs to the set of stretches that contact 1, i.e., $\delta_{l j}=1$. Inequality (1.11) requires the start time of the first stretch 1 to be greater than the start time of the Winter Plan in manoeuvring area $\mathrm{Z}_{0}$. Inequality (1.12) is an operating restriction which establishes that stretches that form the runways must not be the final stretches in the queue of stretches to processed, rwy being the subset of stretches that form the runways. Restriction (3.13) defines $R_{\max z}$ for each subset $\mathrm{z}$ of significant stretches. The inequalities (3.14a) and (3.14b) define $\mathrm{l}_{\mathrm{z}}$ for each set $\mathrm{z}$ of significant stretches, and $\mathrm{l}_{\text {total }}$ for the whole manoeuvring area, respectively.

The problem is now defined for the entire manoeuvring area. However, taking the conclusions resulting from the analysis into account we propose a method of problemsolving that divides the manoeuvring area into $\mathrm{W}$ zones and establishes connecting stretches that become the starting and end points of each of the proposed zones. Therefore, we will consider $\mathrm{W}$ zones in the manoeuvring area and each of these zones will correspond to a subset $\mathrm{i}$ of stretches of the set $\mathrm{J}=(1,2, \ldots, \mathrm{n})$ of $\mathrm{N}$ stretches that make up the manoeuvring area.

Each zone consists of one or more stretches i, and form $\mathrm{W}$ subsets whose union $\mathrm{Zn}$ ' is equal to $\mathrm{J}$. Where the subset $\mathrm{Zn}_{\mathrm{z}}$ of the set $\mathrm{Zn}^{\prime}=\left(\mathrm{Zn}_{1}, \mathrm{Zn}_{2}, \ldots, \mathrm{Zn}_{\mathrm{z}}, \ldots, \mathrm{Zn}_{\mathrm{w}}\right)=\mathrm{J}$. = J. Where stretch $y$ is one of the stretches belonging to the subset $Z_{n_{z}}=\left(1,2, \ldots, y, \ldots, p_{z}\right)$. 
Zone $\mathrm{Zn}_{\mathrm{z}}$ has $\mathrm{p}_{\mathrm{z}}$ stretches of set $\mathrm{J}$ which only belong to $\mathrm{Zn}_{\mathrm{z}}$ and do not belong to any other zone of the manoeuvring area. Therefore:

$\mathrm{Zn}_{1} \cup \mathrm{Zn}_{2} \cup \ldots \cup \mathrm{Zn}_{\mathrm{z}} \cup \ldots \cup \mathrm{Zn}_{\mathrm{h}}=\mathrm{Zn}^{\prime}=\mathrm{J} \quad \mathrm{Zn}_{\mathrm{i}} \cap \mathrm{Zn}_{\mathrm{j}}=\varnothing$ con $\mathrm{i}, \mathrm{j} \in(1,2, \ldots, \mathrm{Z}, \ldots, \mathrm{w})$

Each zone starts in stretch 1 and ends in any of the stretches that share a common vertex with stretch 1 of the next zone. This vertex is called Final Node and endnode is the subset of stretches that converge on the final node. The inequality which requires the snow-clearing process of a zone to end on some stretch of the subset endnode is as follows:

$$
\sum_{i \in e n d n o d e} \sum_{j=1}^{n} x_{i j}^{k}=1 \quad i \in \text { endnode } \quad k=m
$$

Therefore, inequality (5.15) replaces inequality (1.12) in all zones except the last one, $\mathrm{Zn}_{\mathrm{w}}$, and is an operational restriction that establishes that the clearing of each zone must finish through one of the stretches contained in the subset of endnode stretches defined for each of the zones.

According to the results of the analysis, the recommended number of stretches in each zone should be between 30 and 40, and should not exceed 50 .

The subsets of the target stretches must be completely contained in one of the zones into which the manoeuvring area is divided so that only the affected subset will be included in each partial solution. In other words, for any $\mathrm{J}_{\mathrm{i}}=\left(1,2, \ldots, \mathrm{t}, \ldots, \mathrm{q}_{\mathrm{i}}\right) \subset \mathrm{J}$, with $\mathrm{i} \in(1$, $2, \ldots, \mathrm{z}, \ldots, \mathrm{h}), \mathrm{J}_{\mathrm{i}}$ belongs to a single zone $\mathrm{Zn}_{\mathrm{j}}$, with $\mathrm{j} \in(1,2, \ldots, \mathrm{z}, \ldots, \mathrm{w})$.

The solution is achieved via successive iterations to approach the final solution. In each iteration the $\mathrm{w}$ zones are processed in the following order: Zone 1, Zone 2,..., Zone $\mathrm{z}$, ..., Zone w.

An outline of the process for arriving at a solution is given in Figure 1. It has the following data and variables:

\section{Iteration data:}

Each zone has common data, such as $\mathrm{p}_{\mathrm{i}}, \delta_{\mathrm{ij}}$, which is independent of the iteration of the process. The first zone starts with an origin time equal to 0 minutes. The next zone $\mathrm{Zn}_{1}$ starts with an origin time of el $\mathrm{R}_{\max }{ }^{\mathrm{Zn} 1}$, the next zone $\mathrm{Zn}_{2}$ has a time of $\mathrm{R}_{\max }{ }^{\mathrm{Zn} 2}$, and so on so that in $\mathrm{Zn}_{\mathrm{w}}, \mathrm{R}_{\max }{ }^{\mathrm{Znw}}=\mathrm{R}_{\max }$ which is the entire manoeuvring area for the actual iteration of the process. The target data of each subset is adjusted with each iteration, thereby approximating the estimated times to the results of the previous iteration. So,

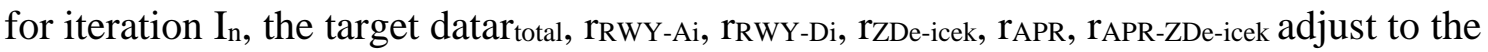
results of iteration In-1 RRWY-Ai, RRWY-Di, RZDe-icek, RAPR, RAPR-ZDe-icek.

\section{Iteration variables:}


For each zone the variables are $\mathrm{si}_{\mathrm{i}}^{\mathrm{k}}, \mathrm{R}_{\mathrm{i}}^{\mathrm{k}}, \mathrm{p}_{\mathrm{i}}^{\mathrm{k}}, \mathrm{x}_{\mathrm{ij}}{ }^{\mathrm{k}} \mathrm{y} \mathrm{R}_{\max }$, with the addition of $\mathrm{R}_{\max } \mathrm{zand} \mathrm{l}_{\mathrm{z}} \mathrm{in}$ the subsets of significant stretches within each zone. The value $R_{\max }$ of one zone is the origin of the times in the following zone, as explained in the paragraph above. The

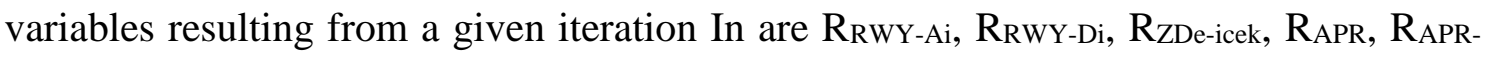

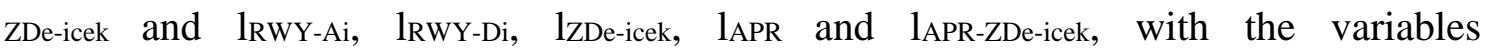
$\mathrm{R}_{\max }{ }^{\mathrm{ZnwIn}}=\mathrm{R}_{\max }{ }^{\text {In }}$ and $\mathrm{l}_{\text {total }}{ }^{\mathrm{ZnwIn}}=\mathrm{l}_{\text {total }}{ }^{\text {In }}$.

The process is finished when in iteration $I_{z}$ the times are not better than those achieved in iteration $\mathrm{I}_{\mathrm{z}-1}$. The final result of iteration $\mathrm{I}_{\mathrm{z}}$ for the variables is $\mathrm{R}_{\mathrm{RWY}-\mathrm{Ai}}, \mathrm{R}_{\mathrm{RWY} \text {-Di, }} \mathrm{R}_{\mathrm{ZDe}}$ icek, RAPR, RAPR-ZDe-icek and lRWY-Ai, lRWY-Di, lzDe-icek, lAPR y lAPR-ZDe-icek, with the variables $\mathrm{R}_{\max }{ }^{\mathrm{ZnwIz}}=\mathrm{R}_{\max }{ }^{\mathrm{Iz}}$ and $1_{\text {total }}{ }^{\mathrm{ZnwIz}}=\mathrm{l}_{\text {total }}$. 


$\begin{array}{cccc}\text { Data } Z \mathrm{n}_{1} & \text { Data } Z \mathrm{n}_{2} & \text { DataZn }_{\mathrm{z}} & \mathrm{DataZn}_{\mathrm{w}} \\ \mathrm{p}_{\mathrm{i}}, & \mathrm{p}_{\mathrm{i},} & \mathrm{p}_{\mathrm{i},} & \mathrm{p}_{\mathrm{i},} \\ \delta_{\mathrm{ij}} \forall \text { Iteration } & \delta_{\mathrm{ij}} \forall \text { Iteration } & \delta_{\mathrm{ij}} \forall \text { Ilteration } & \delta_{\mathrm{ij}} \forall \text { Iteration }\end{array}$

$\delta_{i j} \forall$ Iteration
$r_{\text {total }} r_{\text {RWY-Ai }} r_{\text {RWY-Di }} r_{\text {ZDe-icek }} r_{\text {APR }} r_{\text {APR-ZDe-icek }}$ for Iteration 1

11

\begin{tabular}{c}
$\downarrow$ \\
$\mathrm{Z}_{0}=0$ \\
$\mathrm{n}_{1}$ \\
Equations \\
$4.2,1.2$ to \\
$1.11,3.13$ \\
$3.14,5.15$ \\
\hline
\end{tabular}

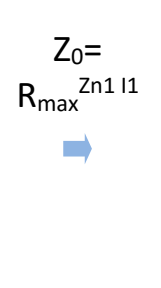

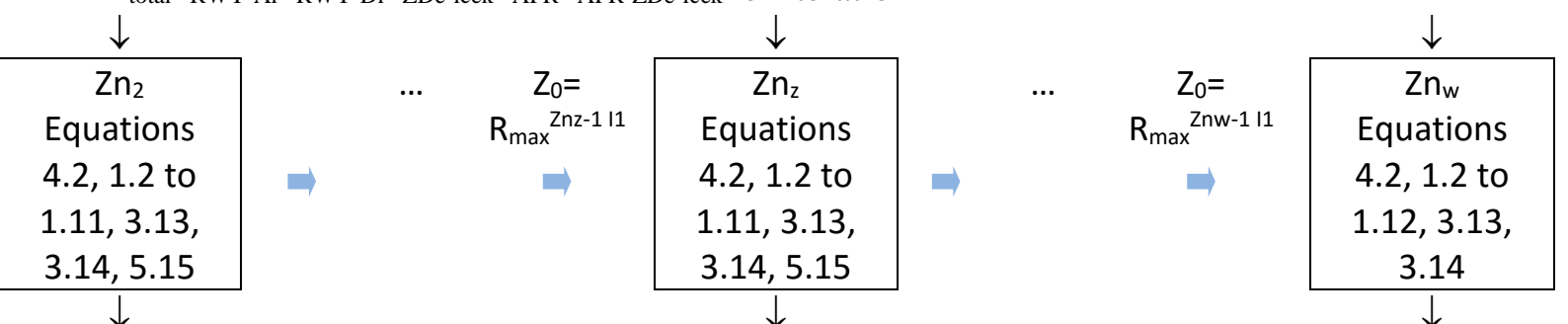

\begin{tabular}{|c|c|}
\hline \multirow{3}{*}{$Z_{0}=0$} & $\downarrow$ \\
\hline & $\mathrm{Zn}_{1}$ \\
\hline & Equations \\
\hline & $4.2,1.2$ to \\
\hline & 1.11, 3.13, \\
\hline & $3.14,5.15$ \\
\hline
\end{tabular}

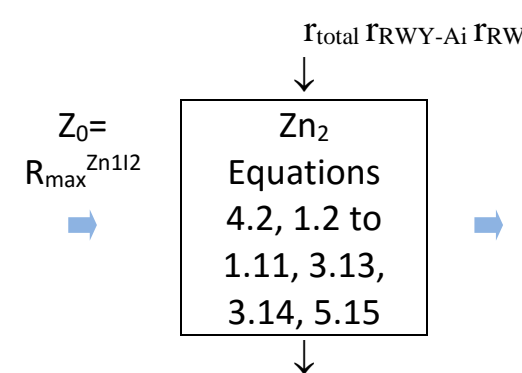

$R_{\text {maxRWY-Ai }} R_{\text {maxRWY-Di }} R_{\text {maxZDe-icek }} R_{\text {maxAPR }} R_{\text {maxAPR-ZDe-icek }}$ and $I_{\text {RWY-Ai }} I_{R W Y-D i} l_{\text {ZDe-icek }} I_{A P R} I_{A P R-Z D e-i c e k}$ for Iteration 2

$\downarrow$

$r_{\text {total }} r_{\text {RWY-Ai }} r_{\text {RWY-Di }} r_{\text {ZDe-icek }} r_{\text {APR }} r_{\text {APR-ZDe-icek }}$ for Iteration $n$

$\downarrow$

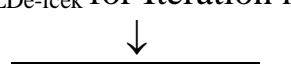

$\downarrow$ 


\begin{tabular}{|c|}
\hline $\mathrm{Zn}_{1}$ \\
Equations \\
$4.2,1.2$ to \\
$1.11,3.13$ \\
$3.14,5.15$ \\
\hline$\downarrow$
\end{tabular}

\begin{tabular}{c|c|}
$\mathrm{Z}_{0}=$ & $\mathrm{Zn}_{2}$ \\
$\mathrm{R}_{\max } \mathrm{Zn} \ln$ & Equations \\
$\Rightarrow$ & $4.2,1.2$ to \\
& $1.11,3.13$ \\
& $3.14,5.15$ \\
\hline
\end{tabular}

\begin{tabular}{|c|c|}
\hline $\begin{array}{c}\mathrm{Z}_{0}= \\
\mathrm{R}_{\max } \mathrm{znzz}^{-1 \mathrm{ln}} \\
\Rightarrow\end{array}$ & $\begin{array}{c}\mathrm{Zn}_{\mathrm{z}} \\
\text { Equations } \\
4.2,1.2 \text { to } \\
1.11,3.13, \\
3.14,5.15\end{array}$ \\
\hline
\end{tabular}

$\mathrm{Z}_{0}=$
$\mathrm{R}_{\max }{ }^{\mathrm{Znw} w-1 \mathrm{ln}}$

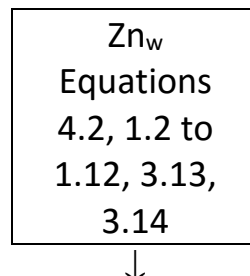

$R_{\max }{ }^{\text {Znwin }}=R_{\text {max }}{ }^{\ln }$ $I_{\text {total }}{ }^{\text {Znwln }}=I_{\text {total }}{ }^{\text {In }}$

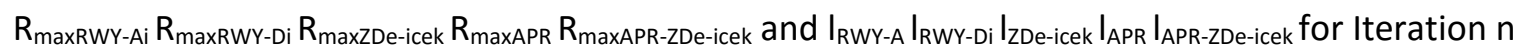

$\sqrt{1}$

Iz

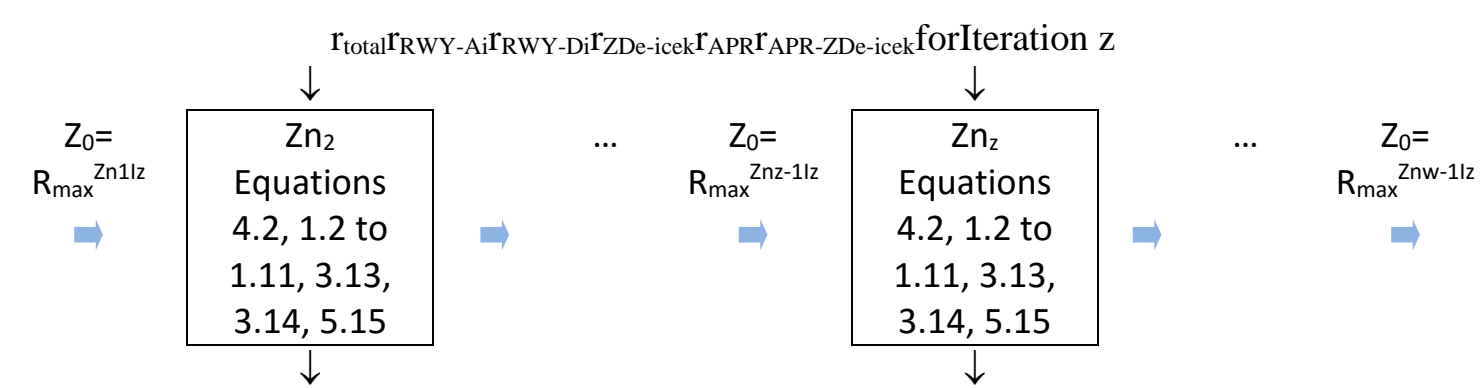

$R_{\text {maxRWY-Ai }} R_{\text {maxRWY-Di }} R_{\text {maxZDe-icek }} R_{\text {maxAPR }} R_{\text {maxAPR-ZDe-icek }}$ and $I_{R W Y-A i} I_{\text {RWY-Di }} I_{\text {ZDe-icek }} I_{\text {APR }} I_{\text {APR-ZDe-icek }}$ for Iteration z

Variables of
$\mathrm{Zn}_{1}$
$\mathrm{~s}_{\mathrm{i}}{ }^{\mathrm{k}}, \mathrm{R}_{\mathrm{i}}{ }^{\mathrm{k}}, \mathrm{p}_{\mathrm{i}}{ }^{\mathrm{k}}$,
$\mathrm{x}_{\mathrm{ij}}{ }^{\mathrm{k}}$ in each
iteration

$$
\begin{gathered}
\text { Variables of } \\
Z_{n_{2}} \\
\mathrm{~s}_{i}{ }^{k}, \mathrm{R}_{\mathrm{i}}{ }^{\mathrm{k}}, \mathrm{p}_{\mathrm{i}}{ }^{\mathrm{k}}, \\
\mathrm{x}_{\mathrm{ij}}{ }^{\mathrm{k}} \text { in each } \\
\text { iteration }
\end{gathered}
$$

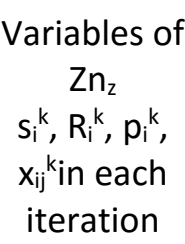

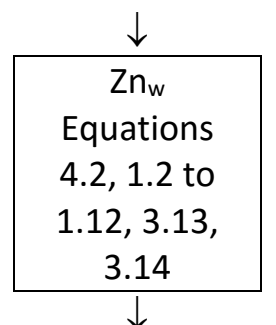

$R_{\max }{ }^{2 n w 1 z}=R_{\max }{ }^{1 z}$ $I_{\text {total }}{ }^{2 n w l z}=\left.I_{\text {total }}\right|^{1 z}$

Figure1: Process for applying the proposed problem-solving method to the problem RM-MA using scheduling theory 


\section{Case Study: Application of the model to manoeuvring area T4S of Adolfo Suárez Madrid-Barajas Airport.}

3.1. Modelling the manoeuvring area.

We will consider a manoeuvring area at Adolfo Suarez Madrid-Barajas Airport, incorporating the apron area of terminal T4S and runways $14 \mathrm{~L}-32 \mathrm{R}$ and $18 \mathrm{~L}-36 \mathrm{R}$ in North configuration, in other words, with 32R for landings and 36R for take-offs. The manoeuvring area consists of an apron with stands, both remote and in front of the terminal building, and the two runways already mentioned used exclusively for takeoffs and landings. We divided the axes of the taxiways and runways into stretches and each was assigned a consecutive number. The stretches are defined by the points of intersection with other stretches.

In total the model has 117 stretches (Figure 2). There are stretches in which snow can be cleared in just one pass and others, such as the runways, which require several passes and with different configurations of the machines. To calculate the performance of the machines we have considered the length of the stretch and have assumed that the snowclearing machines operate at a speed of $40 \mathrm{~km} / \mathrm{h}$. The assumption is that all stretches undergo one pass except for the runway, which requires four. In each stretch the snowclearing operation will be carried out at constant speed except at the beginning and the end of the stretch where the speed tends to decrease. This variation is considered to be negligible for the purposes of the theoretical calculation. The times suggested by the model were compared with those achieved in live simulations to validate the performance. In the event of a snow-clearing machine operating at a different speed, the performance will be adapted. 


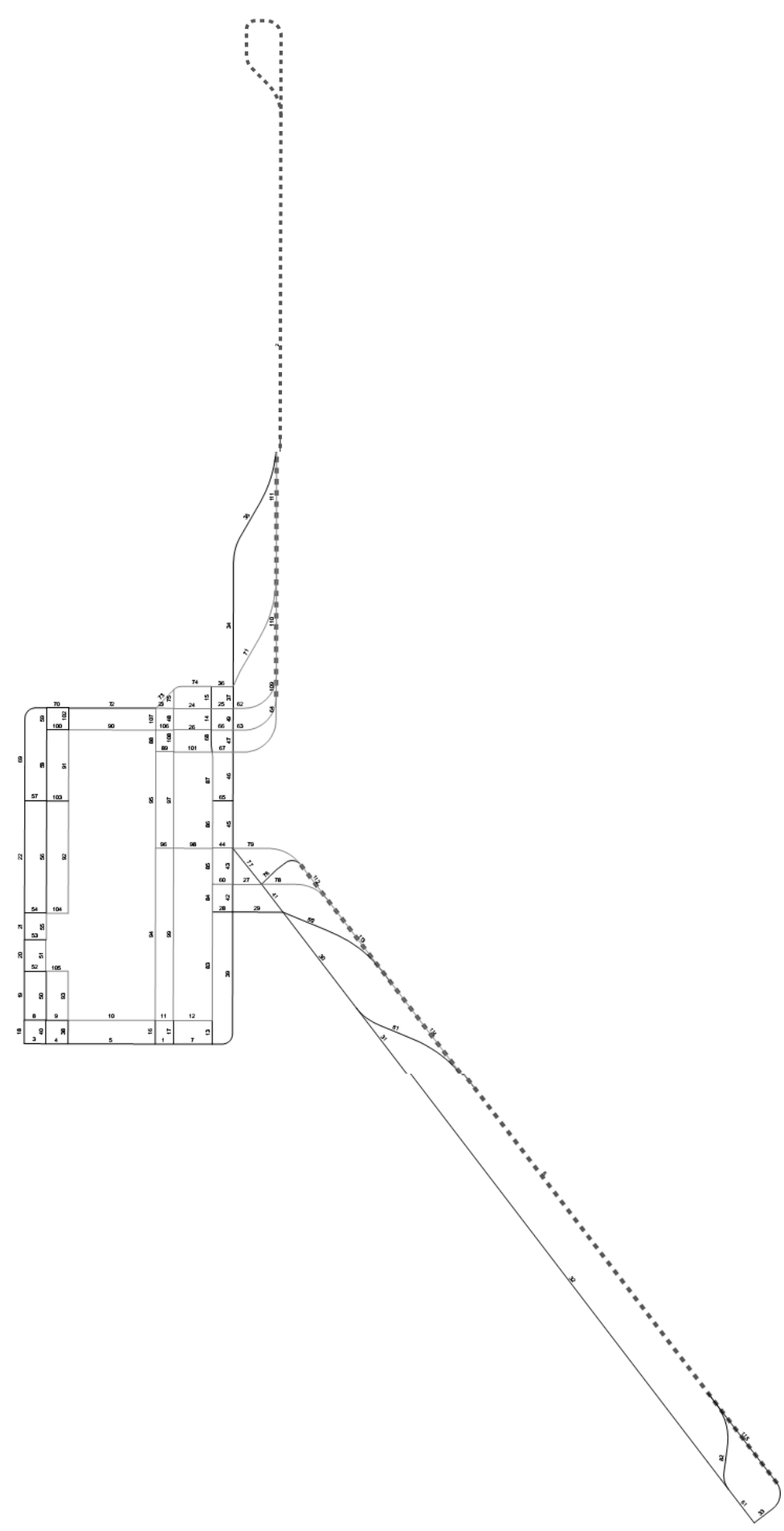

No. of stretches: 117

Length: $\quad 36,289 \mathrm{~m}$

Figure2: Configuration of the manoeuvring area T4S used for the computational tests 


\subsection{Particularisation of the problem-solving methodology}

Bearing in mind the conclusions of the analysis carried out on the method, we proceeded to solve the problem using successive iterations to approach the final solution. In each iteration the three zones, Zone 1, Zone 2 and Zone 3, were processed. (Figures 3, 4, 5 and 6).

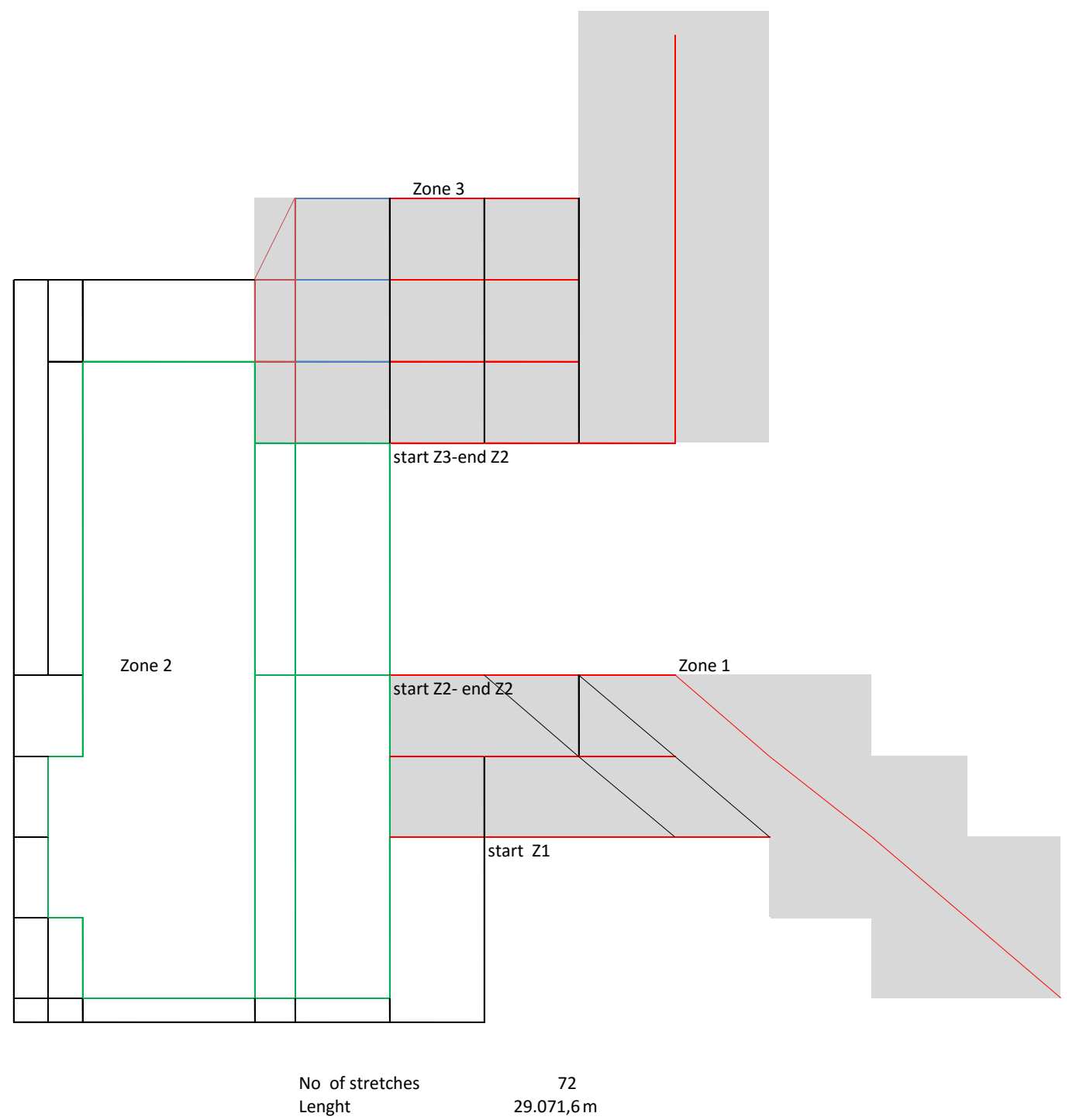

Figure3: Configuration of the manoeuvring area T4S used for the computational tests by zone 


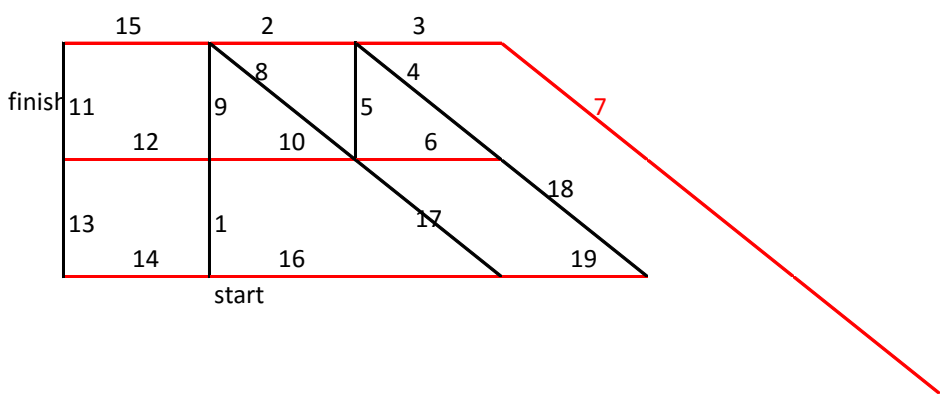

Figure4: Configuration of manoeuvring area T4S, Zone 1

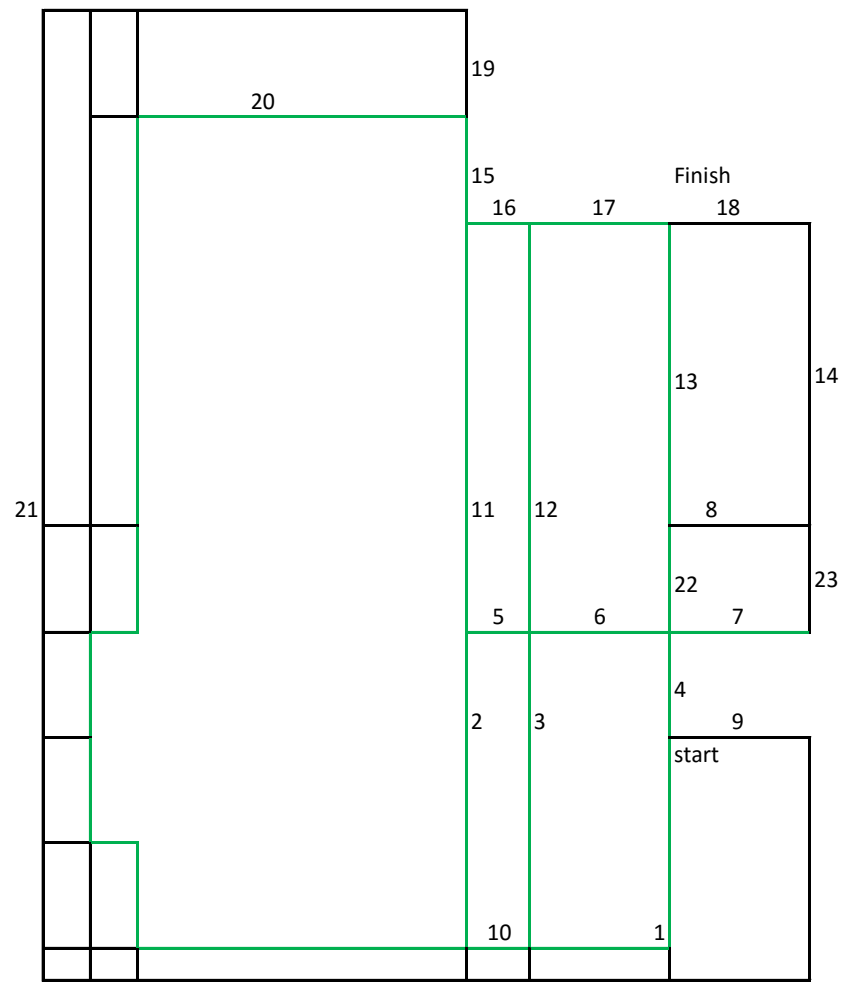

Figure5: Configuration of manoeuvring area T4S, Zone 2 


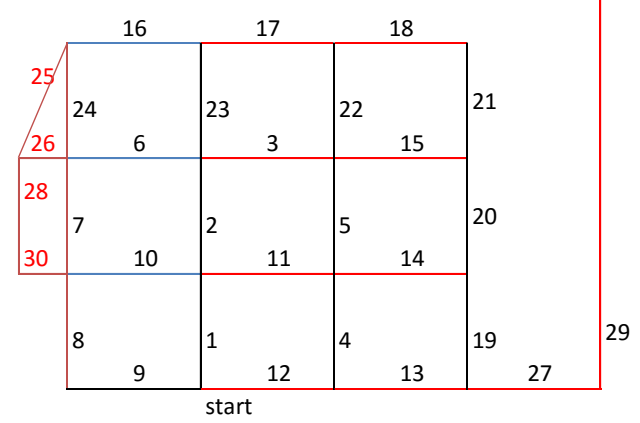

Figure6: Configuration of manoeuvring area T4S, Zone 3

Given the geometry of the manoeuvring area, $\mathrm{H}$ subsets of significant points were particularised into five subsets. We considered one landing runway, one take-off runway, one de-icing apron and, therefore, just one subset of stretches to access the deicing area from the apron, and one apron.

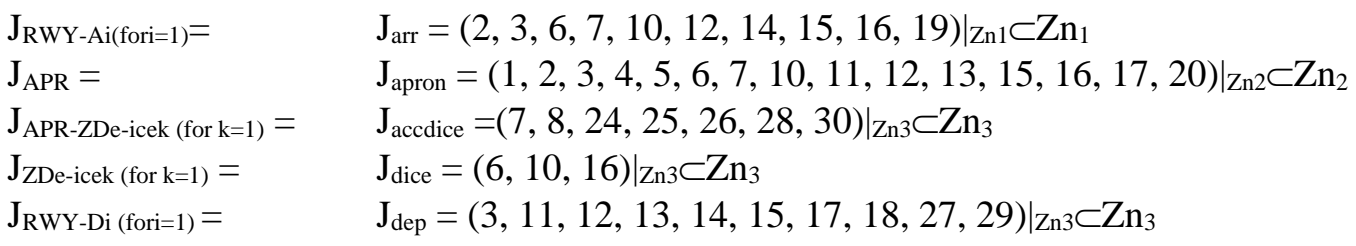

The general problem-solving model is particularised for the manoeuvring area proposed (Fig. 7). 
Data $\mathrm{Zn}_{1}$

$\mathrm{p}_{\mathrm{i}}, \delta_{\mathrm{ij}}$ for

$11,12,13$

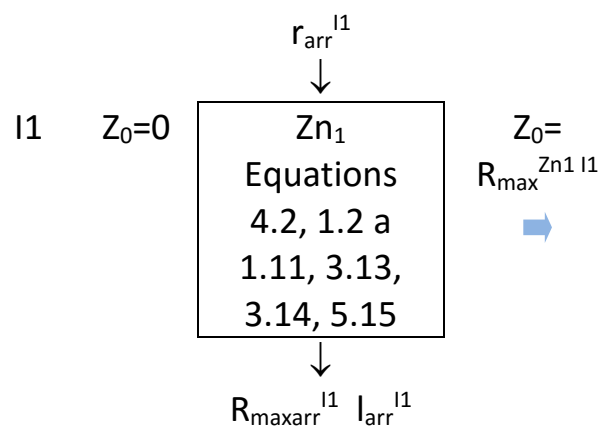

$\sqrt{1}$

12

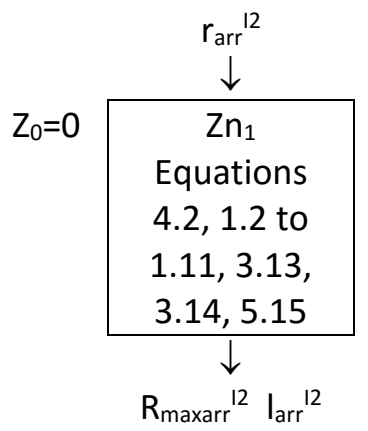

$\sqrt{1}$

13
Data $\mathrm{Zn}_{2}$

$\mathrm{p}_{\mathrm{i}}, \delta_{\mathrm{ij}}$ for

$11,12,13$

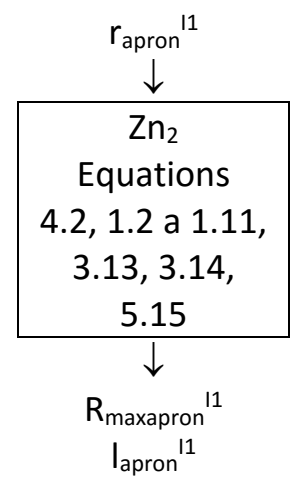

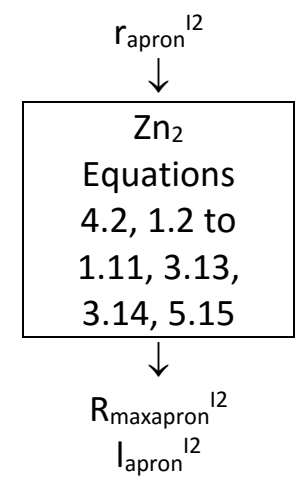
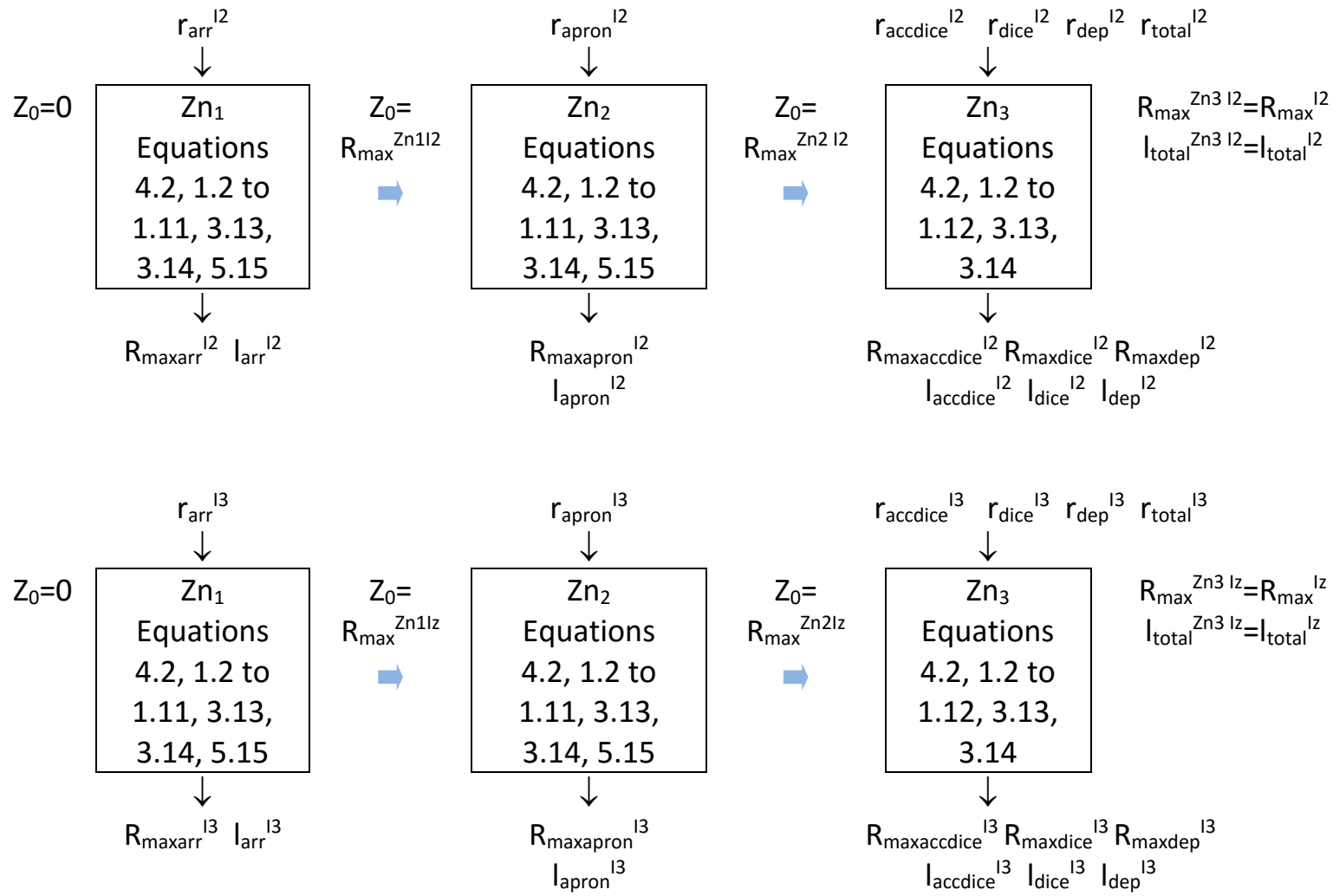

Variables of

$$
\mathrm{Zn}_{1}
$$

$s_{i}^{k}, R_{i}^{k}, p_{i}^{k}, x_{i j}{ }^{k}$

in each

iteration
Variables of
$\mathrm{Zn}_{2}$
$s_{i}^{k}, R_{i}^{k}, p_{i}^{k}, x_{i j}^{k}$
in each
iteration

Figure7: Process to apply the particularised solution method to the manoeuvring area of T4S 


\subsection{Computational Results}

Figures 8, 9 and 10 demonstrates the results of the final iteration.

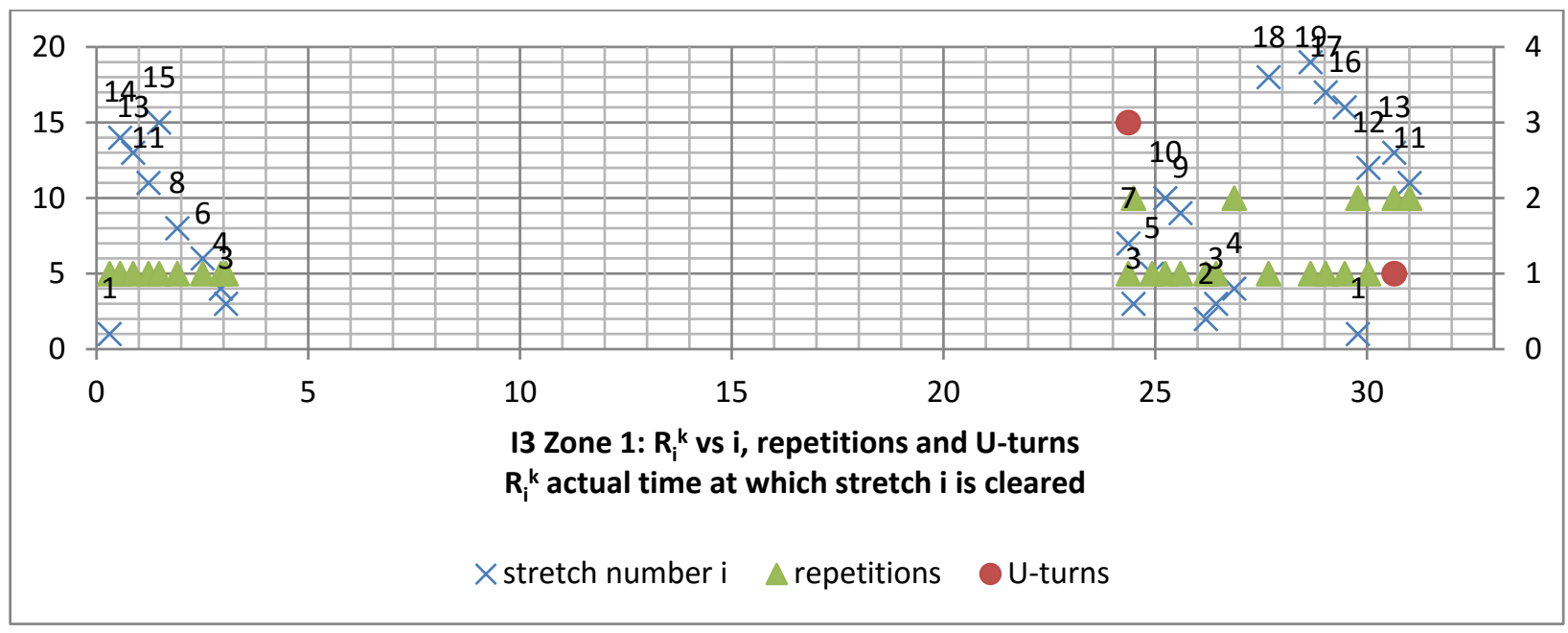

Figure8: Results Zone 1 Iteration 3

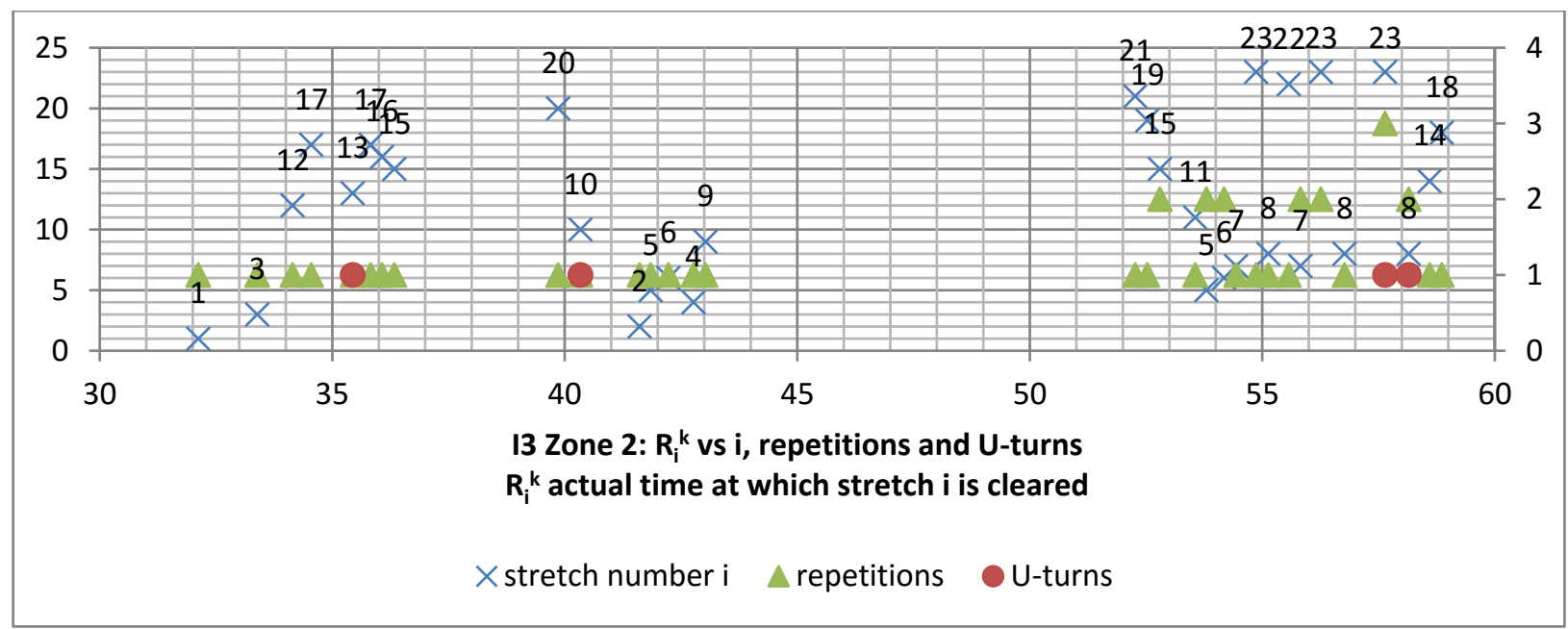

Figure9: Results Zone 2 Iteration 3

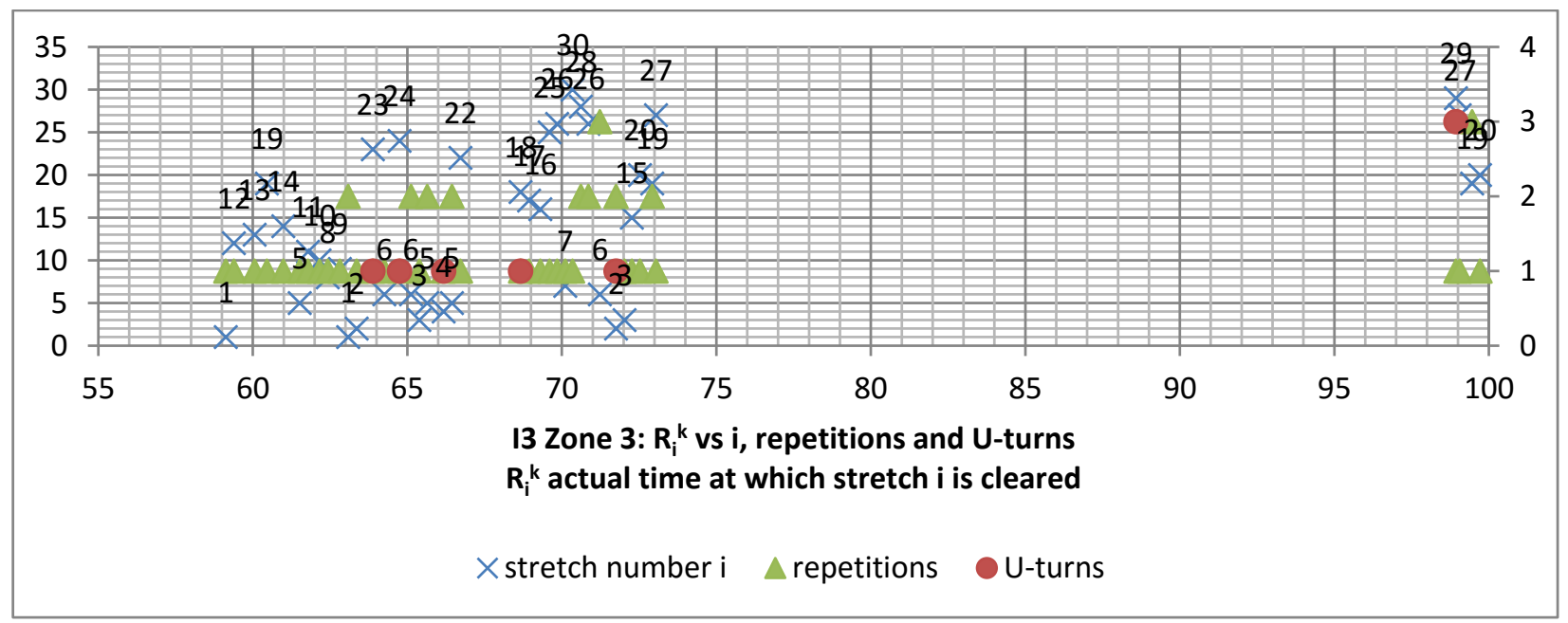

Figure10: Results Zone 3 Iteration 3 


\section{Conclusions and Discussion}

There is an optimal solution for removing snow from stretches of the manoeuvring area. In this article we have presented an algorithm for a single machine based on algorithms proposed by the authors Bianco et al. 1997 and Guinet 1993 for DMAN and AMAN problems, to resolve RM-MA problem, and a method of resolution based on an iterative process in which the manoeuvring area is divided into zones with a starting node and a final node.

Each zone must accommodate subsets of significant stretches from the point of view of Winter Operations. The plan covers runways, rapid exit taxiways and taxiways up to the apron. It also includes the stand apron, taxiways from the stand apron to the de-icing apron, take-off runways and taxiways providing access to the head-of-runway from the de-icing zone. The aim of the method proposed in this article is to optimise the time taken by a convoy of machines to remove snow. The algorithm takes account of the technology of the snow-clearing machines, and the width of the taxiways and runways. The results of the method, such as the estimated time taken to remove snow during the contingency plan, should be incorporated into the sequencing of arriving and departing flights.

\section{References}

References in indexed publications:

1. Bianco, L., Dell'Olmo, P. and Giordani, S., 1997. Scheduling Models and Algorithms for TMA Traffic Management. Modelling and Simulation in Air Traffic Management eds. 139-167.

2. Guinet A, 1993. Sequence-Dependent Jobs on Identical Parallel Machines to Minimize Completion Time Criteria. International Journal Production Research, 22(7), 1579-1594.

Other references:

1. AENA, S.A., 2013. $9^{\text {th }}$ Winter Conference, Huesca, España. www.aena.es.

2. Eurocontrol, Airport CDM Coordination Group, 2009. Airport CDM steps to efficiency.

http://www.eurocdm.org/library/eurocontrol/airport_cdm_steps_to_efficiency.pdf.

3. European Aviation Safety Agency (EASA), 2010. Runway Friction and Aircraft Braking: The Way Forwardhttp://easa.europa.eu/system/files/dfu/events-docs2010-11-03-EASA-Runway-Friction-Aircraft-Braking-Workshop-Summaryand-Conclusions.pdf. 